\title{
Determination of Sight Distance Requirements for Finnish Level Crossings
}

\author{
Veli-Pekka Kallberg $^{*}, 1$ and Anne Ahtiainen ${ }^{2}$ \\ ${ }^{I}$ VTT Technical Research Centre of Finland, Finland \\ ${ }^{2}$ Finnish Transport Agency, Finland
}

\begin{abstract}
Safety at level crossings is a major concern for Finnish railways. Less than a quarter of all 4,061 level crossings are equipped with active warning devices, mainly barriers but also warning lights and bells. Especially at passive level crossings it is entirely up to the road user to know whether it is safe to cross the railway. However, the environment should support road users and infrastructure managers should provide conditions where safe behaviour is possible. Perhaps the most important criterion then concerns sight distance conditions at the level crossing. A minimum requirement is that a road user stopped before the level crossing must be able to traverse the railway in less time than it takes for an approaching train to arrive at the level crossing from the point where the road user can first see it. Examples of current sight distance guidelines and their reasoning in selected countries are described. A proposal for new Finnish sight distance guidelines is made. The proposal for required sight distances consists of a minimum sight distance from the road of 5-8 metres from the nearest rail to the railway, and a minimum distance at which a road user approaching the level crossing must be able to see it.
\end{abstract}

Keywords: Level crossing, grade crossing, sight distance.

\section{INTRODUCTION}

Accidents at level crossings are a major safety issue for Finnish railways. At the end of 2009 there were 3,376 level crossings on the state railway network: 2,929 on main railway lines and 447 on secondary lines. In addition, there were 685 level crossings on private tracks. The number of level crossings has nearly halved since the early 1970s.

At the end of 2009740 level crossings were provided with barriers, 78 with sound and light warning devices and 17 with a simple light warning device. The remaining 3,226 level crossings were equipped with passive warning signs, usually a St. Andrew's cross only.

The number of trains per day is typically less than 20 at passive level crossings, and above 30 at roughly $25 \%$ of active level crossings. The estimated volume of road traffic is less than 10 vehicles per day at two out of three passive level crossings and more than 200 vehicles per day in less than half of active level crossings.

In 1999-2009 the annual number of reported level crossing accidents was between 42 and 64 and resulted on an average in eight fatalities and four serious injuries. Most accidents occurred at passive crossings, where road and rail traffic volumes are low.

Responsibility for the safety of level crossings lies mainly with the Finnish Transport Agency (until 1.1.2010 Finnish Rail Administration RHK), which also provides a major part of the funding for safety measures. Over the past few decades RHK has reduced the number of level crossings at a pace of 50-100 per year. Since the early 1970s barriers

*Address correspondence to this author at the P.O. Box 1000, FIN-02044 VTT, Finland; Tel: +358 20722 4591; Fax: +358 20722 7000;

E-mail: Veli-Pekka.Kallberg@vtt.fi (usually half-barriers) have been installed at more than 700 level crossings.

At level crossings road users must be prepared to give way to trains. This is usually required by law, but it is also a natural rule since it takes a lot more time and distance to stop a train than a car at similar speed. The stopping distance of a train is typically several hundred metres and typically at least 10 times longer than that of a road vehicle. Furthermore, trains cannot change direction to avoid a collision in the same way as road vehicles.

At active level crossings road users are informed about an approaching train with sound and light warning devices or barriers so that it is not necessary for them to see the train. At passive level crossings, however, road users must be able to see the approaching train so far in advance that they can be certain that traversing the track is safe if there are no trains in sight. It is clear that adequate sight conditions from the road to the railway are a necessary precondition for level crossing safety, especially at passive level crossings.

\section{BASIC CONCEPTS}

The essential sight distance requirements at level crossings consist of the three potential measurements illustrated in Fig. (1):

- $\quad S_{\text {Stop }}$ is stopping sight distance, which is the distance at which the driver approaching the level crossing must be able to see it so that the vehicle can be stopped at a distance $d_{\text {Stop }}$ before the level crossing. $d_{\text {Stop }}$ is typically a few metres from the nearest rail

- $\quad S_{S}$ is shorter of the two distances measured along the railway. It is defined as the distance at which the driver of a vehicle approaching the level crossing at typical speed or at the speed limit should see the railway in order to cross it safely without reducing 
speed, if there are no approaching trains within distance $S_{S}$ to the level crossing.

- $\quad S_{L}$ is the longer of the two distances measured along the railway. It is defined as the distance at which the driver of a vehicle stopped in front of the level crossing must see to be able to traverse the level crossing if there are no trains approaching within distance $S_{L}$ to the level crossing.

The lines $S_{S}$ and $S_{S}$ together with lines connecting their ends to the road user form triangles, which must be clear of sight-restricting obstacles.

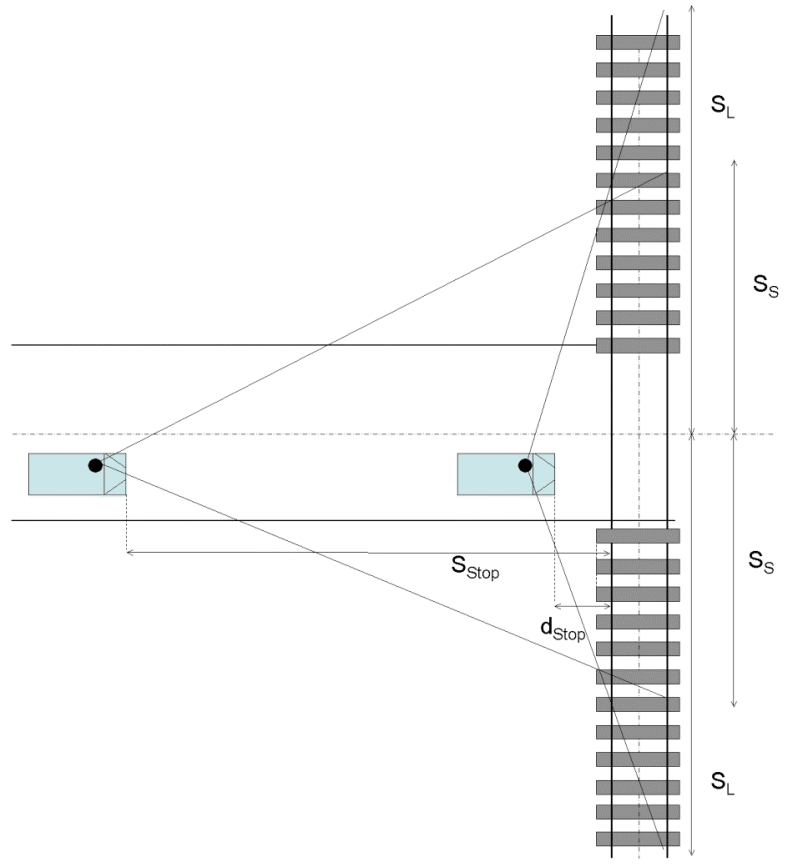

Fig. (1). Relevant sight distance at level crossings. See text for explanation.

\section{COMPARISON OF SIGHT DISTANCE REQUIRE- MENTS IN SELECTED COUNTRIES}

Current Finnish guidelines concerning sight distances at level crossings concern only the measure $S_{L}$ in Fig. (1). At level crossings of a single railway track, $S_{L}$ (metres) must be at least 6 times the maximum speed of the train $(\mathrm{km} / \mathrm{h})$ (Finnish Rail Administration 2004). This means that road users have at least $21.6 \mathrm{~s}$ to cross the track. For train speeds of $30,50,80,100$ and $120 \mathrm{~km} / \mathrm{h}$ the required sight distances at crossings of a single track are 180, 300, 480, 600 and 720 metres, respectively. At level crossings with more than one track, the sight distance requirement is increased by $0.3 \times n \times v$, where $n$ is the distance in metres between the centre lines of the furthest tracks and $v$ is the speed of the train $(\mathrm{km} / \mathrm{h})$.

It is not clear, however, on what grounds this current rule was decided, how well it takes into account safety requirements, or whether it leads to unnecessarily long sight distances that could be detrimental to railway operators if it leads to the reduction of train speeds. Therefore it was decided to make a well-founded proposal for sight distance requirements for Finnish level crossings.

Sight distance requirements in different countries are usually expressed by a formula in which train speed is the main explanatory variable. Other explanatory variables include e.g. vehicle type or length, the distance different kinds of road vehicles need to travel to cross the track, and assumptions concerning the speed and acceleration of road vehicles. In some cases also the vertical alignment of the road and crossing angle are taken into account (Table 1).

The equations used in different countries are given in Table 2 and the resulting sight distance requirements in Fig. (3), which shows that there are considerable differences among countries.

The distance from the nearest rail at which road users approaching the level crossing can first see the level crossing is not mentioned in the Finnish guidelines [1]. It is indicated, however, that the obligatory St. Andrew's crosses must be located so that road users can see them at a distance that is at least as long as the stopping sight distance of road vehicles (distance travelled during reaction time and braking). The guidelines in the U.S.A., Canada and New Zealand, for example, indicate that road users must be able to see the level crossing at a distance that is greater than the stopping sight distance [2-4]. The greater the speeds on the road, the further from the level crossing drivers must be able to see it.

Table 1. Variables Used in the Determination of Sight Distance Requirement at Level Crossings of a Single Railway Line in Different Countries

\begin{tabular}{|c|c|c|c|c|c|}
\hline & Finland & U.S.A. & Canada & Sweden & New Zealand \\
\hline Speed of train & $\mathrm{X}$ & $\mathrm{X}$ & $\mathrm{X}$ & $\mathrm{X}$ & $\mathrm{X}$ \\
\hline Maximum speed of road vehicle & & $\mathrm{X}$ & & & \\
\hline Acceleration of road vehicle & & $\mathrm{X}$ & & & $\mathrm{X}$ \\
\hline Departure time $^{1}$ & & & $\mathrm{X}$ & & \\
\hline Vertical alignment of road & & & & & $\mathrm{X}$ \\
\hline Crossing angle & & & & & $\mathrm{X}$ \\
\hline
\end{tabular}

${ }^{1}$ In Canada the sight distance requirement depends on "departure time", which means "the time required for the vehicle to completely clear the crossing safely". The guidelines do not give a precise method for determining this departure time, but gives acceleration curves for different vehicle types as a guide. Departure time is at least $10 \mathrm{~s}$. 
Table 2. Formulas Used in Different Countries for Determination of the Required Sight Distance from the Road to the Railway Track at Level Crossings

\begin{tabular}{|c|c|c|}
\hline Country & \multicolumn{2}{|l|}{ Equation } \\
\hline Finland & $s=6 \cdot v_{T}+0.3 \cdot n \cdot v_{T} \ldots$ & (1) $[1]$ \\
\hline U.S.A. & $d_{T}=\frac{v_{T}}{3.6}\left(\frac{v_{G}}{a}+\frac{L+2 D+W-d_{a}}{v_{G}}+J\right) \ldots$ & (2) [2] \\
\hline Canada & $D_{\text {Stopped }}=v_{T} \cdot T_{d} \ldots$ & (3) $[3]$ \\
\hline New Zealand & $s_{3}=\frac{v_{T}}{3.6} \mid J+G_{S} \sqrt{\frac{2 \cdot\left(\frac{W_{R}}{\tan Z}+\frac{W_{T}}{\sin Z}+2 C_{V}+L\right)}{a}}$ & (4) $[4]$ \\
\hline Sweden & $s=3 \cdot v_{T} \ldots$ & (5) $[5]$ \\
\hline
\end{tabular}

See also Fig. (2) for explanation of variables.

$s=\mathrm{s}_{3}=d_{T}=D_{\text {Stopped }}=$ required sight distance from the road to the track (for vehicles stopped in front on a single track level crossing) $v_{T}=$ train speed

$\mathrm{n}=$ distance in metres between centre lines of the furthest tracks at level crossings with more than one track.

$v_{G}=$ maximum speed of road vehicle

$a=$ acceleration of road vehicle

$L=$ length of road vehicle

$D=$ Distance of the front of the vehicle from the nearest rail in the initial position

$W=W_{T}=$ distance between outer rails

$d_{a}=$ distance the vehicle travels while accelerating to maximum speed in first gear $\left(=v_{G}{ }^{2} / 2 a\right)$

$W_{R}=$ width of road (travelled way)

$T_{d}=$ departure time (time needed to cross the track)

$J=$ sum of the perception time and the time required to activate the clutch or automatic gear, assumed to be 2 seconds

$G_{S}=$ grade correction factor (1.00 at zero grade and 1.12 at $2 \%$ uphill, for example)

$\mathrm{Z}=$ angle between road and railway (degrees)

$\mathrm{C}_{\mathrm{V}}=$ clearance from the vehicle stop line to the nearest rail

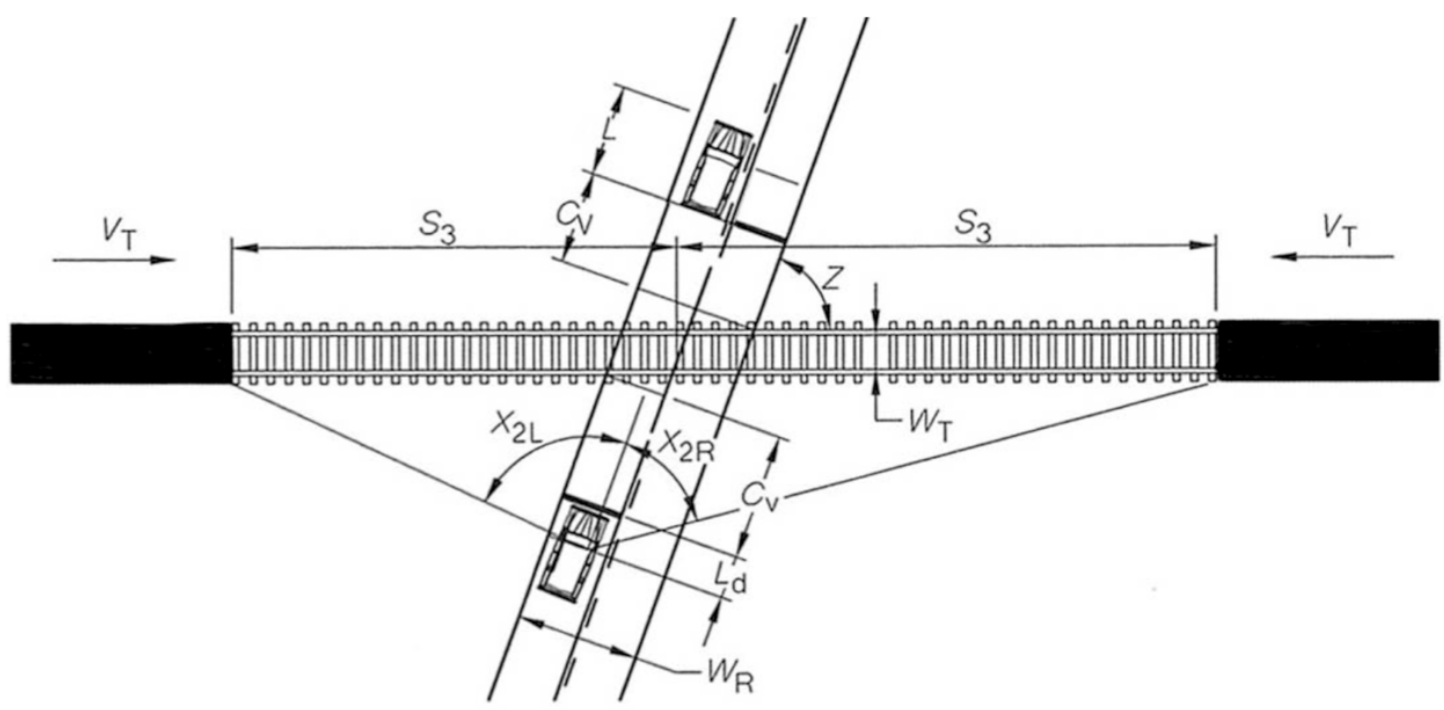

Fig. (2). Measures used in the determination of sight distance requirements at level crossings [4].

\section{BASIC PRINCIPLES FOR SETTING OF SIGHT DISTANCE REQUIREMENTS}

The main goal of the proposed new sight distance requirements was to guarantee safe crossing conditions for road users, meaning that it is possible for all normal, attentive and motivated road users to cross the track safely in normal environmental conditions. On the other hand, unnecessarily long sight distance requirements should be avoided, because long sight distances are often difficult to achieve and excessive sight distance requirements may lead to unnecessary reductions of train speed.

Normal condition of road users above means for drivers of motor vehicles that they fulfil the general requirements for drivers (e.g. requirements concerning driving licence and driver condition). For pedestrians, cyclists, moped drivers 
and drivers of vehicles for which a driving licence is not required, it is assumed that they are capable of comply with traffic rules.

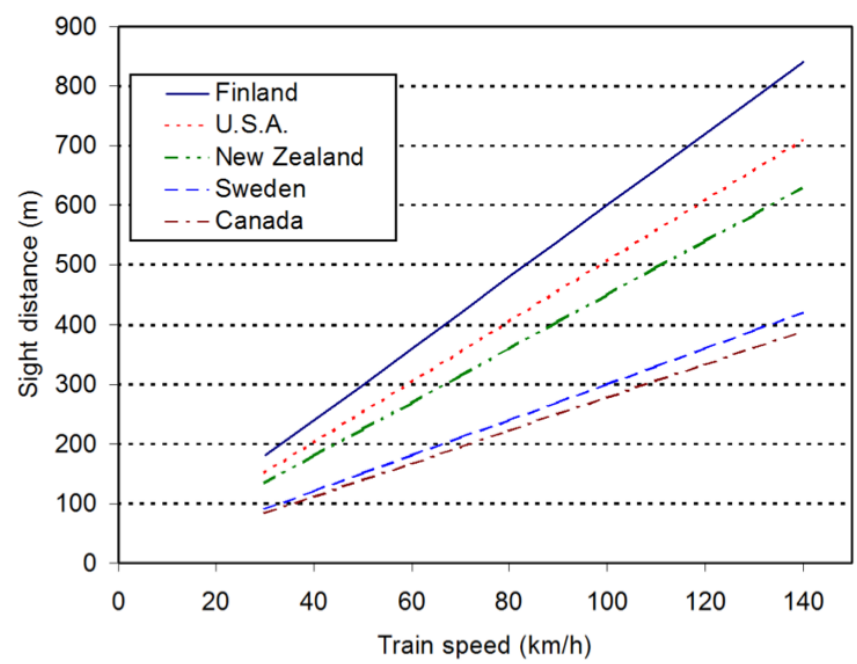

Fig. (3). Required sight distance from the road to the railway in different countries for level crossings of a single track and for $25 \mathrm{~m}$ long vehicle combinations.

Normal environmental conditions above means all common light, weather and road surface conditions with the following exceptions:

- Dense fog, rain or snowfall prevents the road user from seeing the approaching rail vehicle
- $\quad$ Slippery road surface (typically ice or snow) impedes vehicle movement in a way that increases the time needed for crossing of the railway.

These exceptions are necessary because the rail infrastructure manager is not responsible for the maintenance of the road and cannot control weather conditions.

When applied to sight distances safe crossing conditions means that each road user traversing the level crossing must be able to cross the track(s) in less time than it takes for the train to arrive at the crossing from the place where the road user can first see the approaching train.

The time it takes for a road user to cross the track or tracks depends on (a) the traversing distance, which road users must travel to cross the railway line(s), and (b) the characteristics of vehicle or pedestrian motion when traversing the crossing. It is assumed that the road user starts traversing the level crossing from a standstill at a location where he/she or his/her vehicle is at a safe distance from the nearest rail.

The other basic requirement for a safe level crossing is that road users approaching it must be able to detect it in time so that they can adjust their speed and even stop before the crossing if needed.

\section{LEVEL CROSSING TYPES AND DIMENSIONING ROAD USERS}

Required sight distance depends on the types of vehicles and road users that are allowed to use the level crossing. Furthermore, the time it takes for each vehicle type to

Table 3. Level Crossing Types and Dimensioning Road Users. In Cases where there were Two Alternatives for Dimensioning Road Users, the One Requiring the Longer Traversing Time is in Bold Text

\begin{tabular}{|c|c|c|c|c|}
\hline Level Crossing Type & Access & $\begin{array}{c}\text { Dimensioning } \\
\text { Vehicle/Road User }\end{array}$ & $\begin{array}{c}\text { Sub- } \\
\text { Category }\end{array}$ & $\begin{array}{l}\text { Slope (Positive } \\
\text { Values } \\
\text { Indicate Uphill) }\end{array}$ \\
\hline \multirow{4}{*}{ Public $(\mathrm{Pu})$} & \multirow{4}{*}{ All vehicles and road users } & \multirow{4}{*}{$\begin{array}{c}25.25 \text { m long truck } \& \text { trailer combination } \\
\text { or } \\
\text { pedestrian }\end{array}$} & $\mathrm{Pu} 1$ & $<0.0$ \\
\hline & & & $\mathrm{Pu} 2$ & $0.0-1.5 \%$ \\
\hline & & & Pu3 & $1.5-3.3 \%$ \\
\hline & & & $\mathrm{Pu} 4$ & $>3.3 \%$ \\
\hline \multirow{4}{*}{ Limited access (Li) } & \multirow{4}{*}{$\begin{array}{l}\text { Truck and trailer combination prohibited, } \\
\text { or all trucks and buses prohibited }\end{array}$} & \multirow{4}{*}{$\begin{array}{c}12 \text { m long truck } \\
\text { or } \\
\text { pedestrian }\end{array}$} & Li1 & $<0.0$ \\
\hline & & & $\mathrm{Li} 2$ & $0.0-1.5 \%$ \\
\hline & & & $\mathrm{Li} 3$ & $1.5-3.3 \%$ \\
\hline & & & Li4 & $>3.3 \%$ \\
\hline $\begin{array}{l}\text { Pedestrians } \\
\text { crossing }(\mathrm{Pe})\end{array}$ & Pedestrians, bicycles (and mopeds) only & Pedestrian & & All \\
\hline $\begin{array}{l}\text { Snow mobile } \\
\text { crossing }(\mathrm{Sm})\end{array}$ & $\begin{array}{l}\text { Snow mobiles and comparable } \\
\text { (off-road) vehicles, pedestrians }\end{array}$ & Snow mobile or pedestrian & & All \\
\hline $\begin{array}{l}\text { Service road crossing } \\
\text { (Sr) }\end{array}$ & $\begin{array}{l}\text { Maintenance vehicles } \\
(<12 \mathrm{~m}) \text {, pedestrians }\end{array}$ & $\begin{array}{c}12 \text { m long truck } \\
\text { or } \\
\text { pedestrian }\end{array}$ & & All \\
\hline $\begin{array}{c}\text { Pedestrian crossing } \\
\text { between platforms }(\mathrm{Pp})^{1}\end{array}$ & $\begin{array}{l}\text { Pedestrians, maintenance and } \\
\text { service vehicles }(<12 \mathrm{~m})\end{array}$ & $\begin{array}{c}12 \text { m long truck } \\
\text { or } \\
\text { pedestrian }\end{array}$ & & All \\
\hline
\end{tabular}


traverse the level crossing depends on the slope of the road. Sight distance requirements were determined separately for six level crossing types, two of which had four subcategories (Table 3).

Dimensioning road users at each level crossing type were selected from road users who may use the crossing. A pedestrian was always one alternative and the potentially slowest vehicle allowed to use the crossing was the other. The dimensioning road users are in bold text in Table 3. For service road crossings and pedestrian crossings between platforms pedestrian was selected as the dimensioning road user even though such crossings are occasionally used also by vehicles for which crossing time is longer than for pedestrians. The reasoning behind this decision is that service road crossings should be provided at least with manual gates and crossings between platforms are used by trucks or similar vehicles only at exceptional situations.

A $12 \mathrm{~m}$ long truck was used as a dimensioning vehicle at level crossings with limited access (type Li) even in cases where trucks and buses are banned, because emergency vehicles like fire engines must be able to use the crossings safely.

\section{MEASUREMENT OF SIGHT DISTANCE}

The required sight distance is measured along the railway. A road user who has stopped in front of a level crossing must be able to see the railway, at a height of 1.1 metres above the furthest rail of the nearest track, over the required sight distance. The eye position of the observer on the road is $8.0 \mathrm{~m}$ from the nearest rail and 1.1 metres above the road surface at public level crossings (type $\mathrm{Pu}$ ) and at level crossings with limited access (type Li). At other level crossing types $(\mathrm{Pe}, \mathrm{Sm}, \mathrm{Sr}, \mathrm{Pb})$ it is assumed that the road user has stopped at a distance of 5 metres from the nearest rail, except at crossings between platforms where this distance can be 2 metres (e.g. in cases where the platform is so narrow that $5 \mathrm{~m}$ from the nearest track is beyond the platform and even on the next railway track).

The distances 5 and 8 metres were selected to take into account that the front of the vehicle can be several meters in front of the driver (see Fig. 4) and to make sure that when the driver's eyes are 8 metres from the nearest rail no part of the vehicle is too close to the railway. Also pedestrians may have pushcarts or they may carry objects that extend well ahead of them.

\section{CALCULATION OF REQUIRED SIGHT DISTANCE}

The required sight distance $S_{L i}$ from the road to the track (corresponding to the distance $S_{L}$ in Fig. 1) is defined from the equation

$$
S_{L i}=v_{T} \cdot\left(\frac{L+d_{R}+W_{G} / 2+W_{O} / 2+W_{R}+W_{T}}{v_{R i}}+t_{S}\right)
$$

\section{where (see Fig. 5)}

$S_{L i}=$ required sight distances from the road to the track at a level crossing category i (see categories in Table 4)

$v_{T}=$ speed of train

$L=$ length of road vehicle

$d_{R}=$ distance of road user or front of vehicle from the nearest rail in the initial position $(7.0 \mathrm{~m}$ for vehicles and 5.0 $\mathrm{m}$ for pedestrians, except at pedestrian crossings between platforms where it can be $2.0 \mathrm{~m}$ )

$W_{G}=\quad$ rail gauge $(1.52 \mathrm{~m})$

$W_{O}=$ width of open space $(5.0 \mathrm{~m}$ according to current railway regulations)

$W_{R}=\quad$ width of rail $(0.07 \mathrm{~m})$

$t_{S}=\quad$ safety margin $(3 \mathrm{~s})$

$v_{R i}=$ mean traversing speed of dimensioning road user type in level crossing category $\mathrm{i}$ (from Table 4)

$W_{T}=$ distance between the centre lines of the furthest tracks in cases where there are several tracks

The mean traversing speeds in Table $\mathbf{4}$ for public level crossings and level crossings with limited access were estimated on the basis of a large number of simulations with an advanced vehicle motion simulator called Vemosim [6], using real vehicle data (a 60-tonne $25.25 \mathrm{~m}$ long Sisu E11M380 truck trailer combination and a 16-tonne $12 \mathrm{~m}$

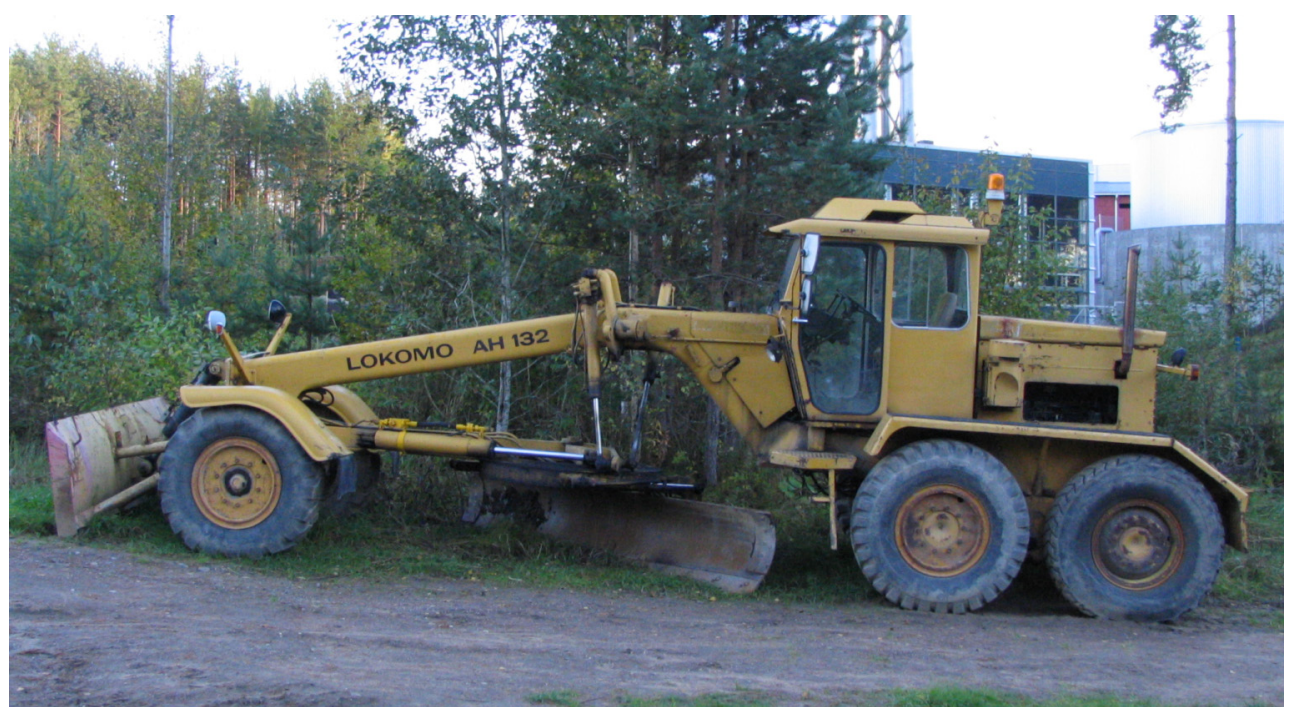

Fig. (4). Blade grader, where the driver sits several metres behind the front of the vehicle. 


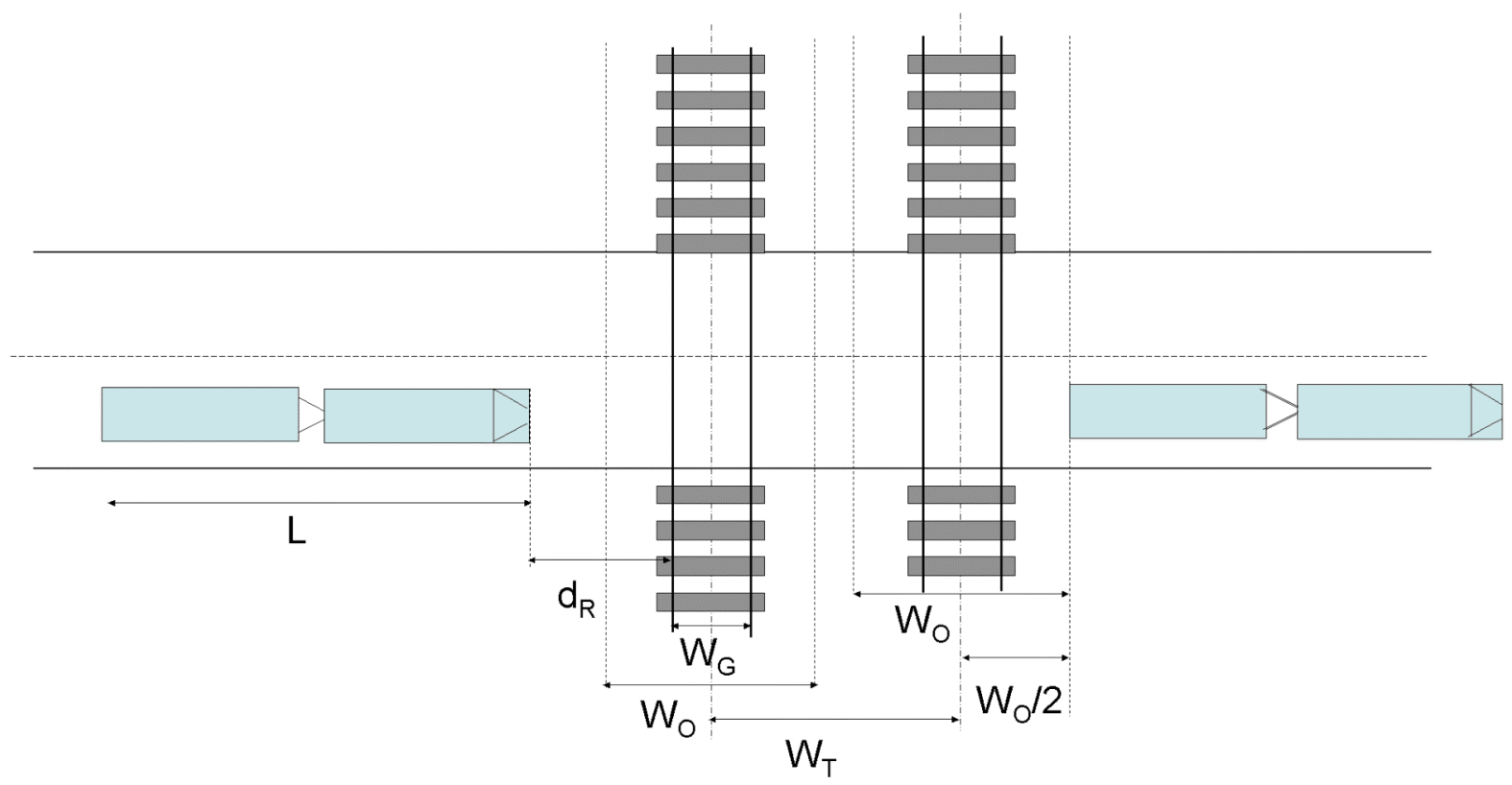

Fig. (5). Dimensions needed for the determination of required sight distance.

long Scania G93M truck). In the simulations the maximum speed of vehicles was limited to $10 \mathrm{~km} / \mathrm{h}$. Other input included the longitudinal slope of the road at existing level crossings.

Table 4. Mean Traversing Speeds for Different Kinds of Level Crossings

\begin{tabular}{|c|c|c|c|}
\hline \multirow{2}{*}{ Level Crossing Type } & \multicolumn{2}{|c|}{ Slope } & Speed $\boldsymbol{v}_{\boldsymbol{R} i}(\mathrm{~m} / \mathbf{s})$ \\
\hline \hline \multirow{4}{*}{ Public level crossing } & Pu1 (i=1) & $<0.0$ & 2.22 \\
\cline { 2 - 4 } & Pu2 (i $=2)$ & $0.0-1.5 \%$ & 1.98 \\
\cline { 2 - 4 } & Pu3 (i=3) & $1.5-3.3 \%$ & 1.87 \\
\cline { 2 - 4 } & Pu4 (i=4) & $>3.3 \%$ & 1.69 \\
\hline \multirow{3}{*}{$\begin{array}{c}\text { Level crossing with } \\
\text { limited access }\end{array}$} & Li1 (i =5) & $<0.0$ & 2.26 \\
\cline { 2 - 4 } & Li2 (i $=6)$ & $0.0-1.5 \%$ & 2.03 \\
\cline { 2 - 4 } & Li3 (i $=7)$ & $1.5-3.3 \%$ & 1.85 \\
\cline { 2 - 4 } & Li4 (i $=8)$ & $>3.3 \%$ & 1.69 \\
\hline Other & All (i $=9$ & All & 0.90 \\
\hline
\end{tabular}

The mean traversing speed for pedestrians was set at 0.9 $\mathrm{m} / \mathrm{s}$, based on measurements of pedestrian speeds at three pedestrian crossings across streets in the city of Helsinki. The total number of speed measurements was 303, the mean speed of pedestrians of all ages was $1.42 \mathrm{~m} / \mathrm{s}$ and the standard deviation of speeds was $0.32 \mathrm{~m} / \mathrm{s}$. The slowest observed speed was $0.7 \mathrm{~m} / \mathrm{s}$ and the speed was lower than $0.9 \mathrm{~m} / \mathrm{s}$ for nine pedestrians ( $3 \%$ of all observations).

It was not considered practical to take into account added traversing distance caused by other than a straight crossing angle (compared to equation 4 in Table 2), since the effect on traversing time would have been small compared to e.g. the 3-second safety margin, which was added to all calculated traversing times as shown in the next section.

\section{SUGGESTED NEW SIGHT DISTANCE REQUIRE- MENTS FROM ROAD TO TRACK}

Sight distance requirements calculated with equation 6 for different level crossing categories are presented in Table 5, together with the current requirements [1]. It can be seen that shorter sight distances than before are required at public level crossings where the slope of the road is less than $1.5 \%$, but for public lever crossings on a steeper uphill longer sight distances are required. The differences between the current and new sight distance requirements at public level crossings range from $-12 \%$ to $+11 \%$.

The current sight distance requirements do not have separate provisions for level crossings with limited access separately; and the distance requirements are the same as for public level crossings. It can be seen from Table 5 that by taking into account that truck and trailer combinations do not use a crossing, sight distance requirements can be reduced considerably - by $25-40 \%$ depending on the gradient of the road.

At pedestrian crossings and crossings between platforms, the required sight distances increase by $13 \%$ compared to the current requirement, except at crossings between platforms when it is assumed that the pedestrian starts traversing at a distance of 2 metres from the nearest rail (instead of 5 metres). In the latter case it decreases by $17 \%$.

The current sight distance requirements do not have separate provisions for snowmobile crossings, and crossings of service roads. The same requirements apply as for public crossings. The new sight distance requirements are $43 \%$ shorter than those in the current regulations.

\section{REQUIRED DETECTION DISTANCE OF A LEVEL CROSSING}

Road users approaching the level crossing must be able to detect it in time so they can adjust their speed and even stop before the crossing if needed. The required detection 
Table 5. Required Sight Distances from Road to Track at Level Crossings of a Single Track

\begin{tabular}{|c|c|c|c|c|c|c|c|}
\hline \multirow{3}{*}{$\begin{array}{l}\text { Train } \\
\text { Speed } \\
(\mathbf{k m} / \mathbf{h})\end{array}$} & \multirow{3}{*}{$\begin{array}{l}\text { Longitudinal } \\
\text { Gradient of the } \\
\text { Road (\%) }\end{array}$} & \multicolumn{6}{|c|}{ Required Sight Distance (m) by Level Crossing Category } \\
\hline & & \multicolumn{2}{|c|}{ Public Level Crossing $^{1}$} & \multicolumn{2}{|c|}{$\begin{array}{c}\text { Level Crossing with Limited } \\
\text { Access }{ }^{1}\end{array}$} & \multicolumn{2}{|c|}{$\begin{array}{l}\text { Pedestrian Crossing, Snow Mobile } \\
\text { Crossing, Crossing of Service Road, } \\
\text { Crossing Between Platforms }\end{array}$} \\
\hline & & New & Current & New & Current & $\mathrm{New}^{3}$ & Current $^{4}$ \\
\hline \multirow{4}{*}{30} & $<0 \%$ & 158 & \multirow{4}{*}{180} & 108 & \multirow{4}{*}{180} & \multirow{4}{*}{$102(74)$} & \multirow{4}{*}{$90 / 180$} \\
\hline & $0 \ldots+1.5 \%$ & 175 & & 117 & & & \\
\hline & $1.5 \% \ldots+3.3 \%$ & 183 & & 126 & & & \\
\hline & $>3.3 \%$ & 200 & & 135 & & & \\
\hline \multirow{4}{*}{50} & $<0 \%$ & 264 & \multirow{4}{*}{300} & 179 & \multirow{4}{*}{300} & \multirow{4}{*}{$170(124)$} & \multirow{4}{*}{$150 / 300$} \\
\hline & $0 \ldots+1.5 \%$ & 292 & & 194 & & & \\
\hline & $1.5 \% \ldots+3.3 \%$ & 306 & & 210 & & & \\
\hline & $>3.3 \%$ & 333 & & 225 & & & \\
\hline \multirow{4}{*}{80} & $<0 \%$ & 422 & \multirow{4}{*}{480} & 287 & \multirow{4}{*}{480} & \multirow{4}{*}{272 (198) } & \multirow{4}{*}{$240 / 480$} \\
\hline & $0 \ldots+1.5 \%$ & 467 & & 311 & & & \\
\hline & $1.5 \% \ldots+3.3 \%$ & 489 & & 336 & & & \\
\hline & $>3.3 \%$ & 533 & & 360 & & & \\
\hline \multirow{4}{*}{100} & $<0 \%$ & 528 & \multirow{4}{*}{600} & 358 & \multirow{4}{*}{600} & \multirow{4}{*}{340} & \multirow{4}{*}{$300 / 600$} \\
\hline & $0 \ldots+1.5 \%$ & 583 & & 389 & & & \\
\hline & $1.5 \% \ldots+3.3 \%$ & 611 & & 419 & & & \\
\hline & $>3.3 \%$ & 667 & & 450 & & & \\
\hline \multirow{4}{*}{120} & $<0 \%$ & 633 & \multirow{4}{*}{720} & 430 & \multirow{4}{*}{720} & \multirow{4}{*}{409} & \multirow{4}{*}{$360 / 720$} \\
\hline & $0 \ldots+1.5 \%$ & 700 & & 467 & & & \\
\hline & $1.5 \% \ldots+3.3 \%$ & 733 & & 503 & & & \\
\hline & $>3.3 \%$ & 800 & & 540 & & & \\
\hline \multirow{4}{*}{140} & $<0 \%$ & 739 & & 502 & & & \\
\hline & $0 \ldots+1.5 \%$ & 817 & 840 & 544 & 840 & 477 & $420 / 840$ \\
\hline & $1.5 \% \ldots+3.3 \%$ & 856 & & 587 & & & \\
\hline & $>3.3 \%$ & 933 & & 630 & & & \\
\hline
\end{tabular}

${ }^{1}$ The distance of the observer is 8 metres from the nearest track (distance $a$ in Fig. 3). The current requirement is $6 \times v_{T}$, where $v_{T}$ is train speed (km/h).

${ }^{2}$ Crossings between platforms are allowed only if the train speed does not exceed $80 \mathrm{~km} / \mathrm{h}$.

${ }^{3}$ The distance of the observer from the nearest track is 5 metres, except at crossings between platforms where it can be between 2 and 5 metres. The values in brackets concern crossings between platforms when the pedestrian starts traversing the railway at a distance of 2 metres from the nearest rail.

${ }^{4}$ For pedestrian crossings and for crossings between platforms the current requirement is $3 \times \mathrm{V}_{\mathrm{T}}$, elsewhere $6 \times \mathrm{V}_{\mathrm{T}}$.

distance or minimum distance at which the driver of the car approaching the level crossing must be able to detect it depends on the speed of the road vehicle, average deceleration during braking, reaction time of the driver and a reasonable safety margin in metres. More precisely, it is suggested that the following required detection distance $s$ be added to the Finnish guidelines.

$$
s=v_{0} t_{R}+\frac{v_{0}^{2}}{2 \cdot a}+d_{S}
$$

where $v_{0}$ is the speed of the road vehicle, $t_{R}$ is the reaction time of the driver, $a$ is the average deceleration during braking, and $d_{S}$ is the distance of the vehicle from the nearest rail when it has stopped. The speed $v_{0}$ should reflect actual driving speeds but does not have to be greater than the prevailing speed limit. In equation 7 , driver reaction time is set at 2 seconds and vehicle deceleration at $2.0 \mathrm{~m} / \mathrm{s}^{2}$, which makes it possible for practically all road users to stop before the level crossing. Deceleration $2.0 \mathrm{~m} / \mathrm{s}^{2}$ corresponds to fairly powerful braking, but it is not even near the maximum deceleration on gravel or paved roads, which usually exceeds $5 \mathrm{~m} / \mathrm{s}^{2}$. On icy or snowy road surface conditions, however, the maximum deceleration can be close to $2.0 \mathrm{~m} / \mathrm{s}^{2}$ or even lower. It is assumed, however, that in such slippery conditions drivers choose a lower speed and thus compensate for reduced road surface friction. The value of $d_{S}$ in equation is 5 meters.

The required detection distance of the level crossing as a function of vehicle speeds is presented in Fig. (6). For example, if vehicle speeds on the road are $60 \mathrm{~km} / \mathrm{h}$ the 
drivers must be able to detect the level crossing no later than 108 meters before the nearest rail in the level crossing.

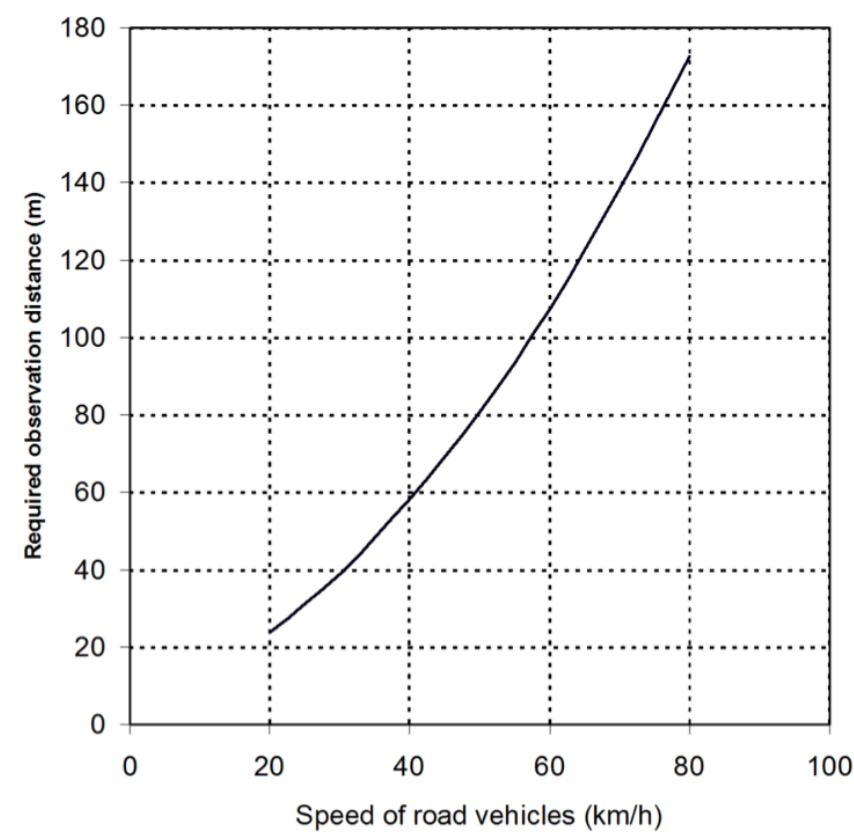

Fig. (6). Required observation distance of a level crossing as a function of the speed of road vehicles.

\section{DISCUSSION AND CONCLUSIONS}

Adequate sight conditions from the road to the railway are an obvious necessity for the safety of road-railway level crossings. It is equally important that road users approaching a level crossing can see it far enough in advance to adjust their speed and stop before the crossing if needed. There is significant variation between countries, however, in what is considered adequate or necessary sight distance in the regulations or guidelines for the design of level crossings. The currently required sight distances in Finland are 18\% longer than in the U.S.A. and $33 \%$ longer than in New Zealand, but twice as long as in Canada and Sweden.

In some countries like the U.S.A. and New Zealand, the prevailing sight distance guidelines are well justified and documented, whereas the reasoning of the Finnish guidelines is less clear. In all countries the required sight distance from the road to the track depends on the maximum speed of trains. In Finland and Sweden the required sight distance at level crossings of a single railway track depends only on train speed, and if the road crosses several railway tracks, also on the distance between the outermost tracks.

The time it takes for a train to arrive at the level crossing from the point where it can first be seen from the vehicle in front of the level crossing decreases linearly with increasing train speed. For a level crossing to be considered safe it is essential that this time is longer that the time it takes for a road user to traverse the level crossing. Therefore sight distance requirements should be based on reliable estimates of how long it takes for road users - and especially the slowest road user allowed to use the crossing - to traverse the level crossing. The guidelines in the U.S.A. and New Zealand, for example, are based on such estimates. A study in Canada has shown that the minimum crossing time of 10 seconds, which is used in the calculation of the required sight distances, is far too short especially for truck and trailer combinations [3].

According to the current Finnish sight distance regulations, road users have 21.6 seconds to traverse the level crossing of a single railway track. Results from simulations using real vehicle and road alignment data show that this time is long enough even for fully loaded truck and trailer combinations of maximum length $(25.25 \mathrm{~m})$ if the road gradient is not greater than approximately $1.5 \%$ uphill. If the road gradient is steeper, longer traversing times and sight distances from the road to the track are needed. The crossing times of truck and trailer combinations based on the Finnish simulations are very similar to those in the Canadian study [3].

It is suggested that it is enough to have only two sight distance requirements for Finnish level crossings - the sight distance from the road to the railway for road users who have stopped in front of the level crossing, and the distance at which road users approaching the level crossing must be able to see it. The third option would be the so-called approach sight distance, which defines the length of railway road users must be able to see from the stopping sight distance and which allows them to traverse the level crossing without reducing their speed if there is no train in sight. In the absence of such an approach sight distance, road users must reduce their speed according to actual sight conditions and even be prepared to stop in front of the level crossing if the visibility to the railway does not open up before they are very close to the level crossing. The approach sight distance is not included in the suggestion for Finnish guidelines because a large part of it typically extends to private land where the Finnish Rail Administration has no right to cut down trees, for example. Furthermore, most Finnish level crossings are on minor roads where speeds are low and the benefits of having the approach sight triangle would be smaller than on high volume roads where speeds are higher. Improving sight conditions further away from the level crossing does not necessarily produce safety benefits either, because drivers tend to increase their speed with increasing sight distance [7].

The suggested new sight distance requirements concern mainly passive level crossings, where there are no devices that automatically warn road users if a train is approaching. At active level crossings with barriers or sound and a light warning device, the sight distance from the road to the track should be as good as can be achieved without unreasonable effort, but not necessarily as long as for passive crossings. Furthermore, it is suggested that the new sight distance guidelines be applied first to new level crossings and that level crossings are upgraded, e.g. in connection with the upgrade of entire railway sections. Then the new guidelines would be applied to approximately 100 level crossings per year.

Application of the guidelines to all passive level crossings is somewhat problematic, because at roughly one third of them the sight distance in at least one of the four quadrants is less than half that required. The introduction of the new guidelines would probably do little to improve the situation, since most level crossings are public crossings for which the sight distance requirements would change by less 
than $12 \%$. The discrepancy between the actual and required sight distances is unlikely to be dramatically reduced in the near future. Nevertheless, inadequate sight distances have very rarely contributed to level crossing accidents. There may be several reasons for this. Firstly, at most crossings traffic volumes on the railway and road are small, and the chances of collision are therefore small. Secondly, sight distance requirements are dimensioned for long and slow vehicles, whereas most vehicles traversing level crossings are shorter and faster, like cars and motorcycles. Finally, sight distance requirements have several built-in "unofficial safety margins". For example road vehicles do not always have to stop before the railway; drivers can make the final decision to cross closer to the railway than is assumed in the guidelines, and vehicles can traverse the crossing faster than is assumed in the guidelines.

\section{ACKNOWLEDGEMENTS}

This paper is based on a study on the formulation of safety guidelines for Finnish level crossings, conducted at VTT Technical Research Centre for the Finnish Rail Administration [8].

\section{REFERENCES}

[1] Finnish Rail Administration, "Ratatekniset määräykset ja ohjeet, osa 9 Tasoristeykset" [Technical guidelines for Finnish railways, part 9 Level crossings], in Finnish, 2004.

[2] Federal Highway Administration, "Railroad-Highway GradeCrossing Handbook. Revised Second Edition”, FHWA-SA-07-010, 2007.

[3] M. Gou, O. Bellavigna-Ladoux and E. Dumont-Mackay, "Impact of Heavy Vehicles on Crossing Safety - Development of an Adapted Design Tool”, Transport Canada, Publication TP 14172E, 2003.

[4] NZ Transport Agency, "Traffic control devices manual, Part 9 Level crossings", 2008.

[5] Banverket, "Plankorsningar, Vägteknisk utformning", Standard BVS 1586.30, in Swedish, 2008.

[6] O.H. Koskinen and J. Sauna-Aho, "Computer simulation of road vehicles for analysing energy consumption, emission amounts, etc.", Proceedings of the 5th World Congress on Intelligent Transport Systems, Seoul, Korea, Paper No. 2064, 1998.

[7] N.J. Ward and G.S.J. Wilde, "Driver approach behaviour at an unprotected railway crossing before and after enhancement of lateral sight distances: An experimental investigation of a risk perception and behavioural compensation hypothesis", Safety Science, Vol. 22, No. 1-3, pp. 63-75, 1996.

[8] V-P. Kallberg, "Tasoristeyksien turvallisuutta koskevat tekniset ohjeet" [Technical guidelines for level crossing safety], VTT Technical Research Centre, Research report VTT-R-11053-08, in Finnish, 2008. 